\title{
Movements of sperm whales in the tropical Pacific
}

\author{
Hal Whitehead ${ }^{1, *}$, Amanda Coakes ${ }^{1}$, Nathalie Jaquet ${ }^{2}{ }_{\text {, Susan Lusseau }}{ }^{1}$ \\ ${ }^{1}$ Department of Biology, Dalhousie University, Halifax, Nova Scotia B3H 4J1, Canada \\ ${ }^{2}$ Center for Coastal Studies, PO Box 1036, 5 Holway Avenue, Provincetown, Massachusetts 02657, USA
}

\begin{abstract}
The movements of female and immature sperm whales Physeter macrocephalus in the tropical Pacific Ocean and adjacent waters are described using photoidentifications over time scales of $3 \mathrm{~d}$ to $15 \mathrm{yr}$ and the tracks of followed groups over scales of 1 to $48 \mathrm{~h}$. The female/immature whales frequently made movements of less than $2000 \mathrm{~km}$ and occasionally made movements of about $4000 \mathrm{~km}$. There were no recorded movements of greater than $5000 \mathrm{~km}$ (for instance, between the eastern and western Pacific). On average, displacements for female/immature whales were about $4 \mathrm{~km}$ after $1 \mathrm{~h}$ of movement, $50 \mathrm{~km}$ after $1 \mathrm{~d}, 200 \mathrm{~km}$ after $3 \mathrm{~d}$, and $1000 \mathrm{~km}$ after periods of $1 \mathrm{yr}$ or more. Members of the 2 principal cultural clans of female and immature sperm whales that use waters near the Galápagos had distinctive movement patterns over all time scales greater than $3 \mathrm{~h}$, with 1 clan's displacements about $50 \%$ greater than the displacements of the other. Displacements were greater than predicted by the correlated random walk over scales of 12 to $48 \mathrm{~h}$ because of autocorrelation in displacement, approximately as predicted by the correlated random walk over periods of days to weeks, but less than predicted by the correlated random walk over scales of years because of boundaries of home ranges. The adaptive movement of sperm whales over large spatial and temporal scales likely contributes to their substantial trophic impact, and reduces geographic population structure. These movements, together with cultural heterogeneity, complicate the management of the species, including the designation of management stocks.
\end{abstract}

KEY WORDS: Sperm whale $\cdot$ Movement $\cdot$ Culture $\cdot$ Density-dependent habitat selection $\cdot$ Population structure Resale or republication not permitted without written consent of the publisher

\section{INTRODUCTION}

Movement is a key element of the ecology of any animal population. Movements have large effects on the flow of genes, diseases and information, and delineate population structure. Movement is thus a vital element of population ecology, trophic ecology, conservation biology, and behavioral ecology (Emlen 1991, Soulé \& Gilpin 1991, Sutherland 1996). Movement patterns can also have a large role in the evolutionary history and evolutionary potential of a species (e.g. Bridle \& Hayes 2007).

Movements occur over a wide range of temporal scales, which have characteristic relevance in other areas of biology. For instance, behavioral ecologists are interested in movements over the time scales during which resources may be depleted, whereas for population geneticists, lifetime movements are more relevant. Within a population of animals, movements vary. From the perspective of trophic ecology, modal movements are important, whereas extreme movements are most significant for genetic structure. Thus, a description of the movements of members of a population should ideally cover all spatial and temporal scales relevant for the species, and include both modal and extreme movements.

The sperm whale Physeter macrocephalus is a species for which an understanding of movement is considered particularly vital. Found over almost all oceans, the species is one of the most trophically significant of marine vertebrates (Clarke 1977) and was a major target of the whaling industry during 3 centuries. We need models of sperm whale movement if we are to understand population structure both genet- 
ically (Lyrholm et al. 1999) and culturally (Rendell \& Whitehead 2003), and to make any realistic attempt to manage the effects of human activities on this species (Dufault et al. 1999). In particular, our understanding of the geographical population structure of the species is poor. The geographical management units for sperm whales used by the International Whaling Commission are contentious and have scant empirical foundation (Donovan 1991).

Movements are integral to the complex population ecology of sperm whales. The sperm whale is longlived (ca. $60 \mathrm{yr}$ ) and slow-reproducing, with females producing 1 calf roughly every 5 yr between the ages of about 12 and 40 (Best et al. 1984), and has extreme sexual segregation. Females and their young form groups of about 20 individuals in the tropics and subtropics. These groups are themselves unstable amalgamations of partially matrilineal and largely stable units of about 11 individuals (Whitehead 2003). Mature males principally use high latitudes, returning to warmer waters to mate on an unknown schedule. Gene distributions show little structure within ocean basins. Lyrholm et al. (1999) found that mitochondrial DNA distributions differ between ocean basins, but nuclear microsatellites do not. Most other measures of population structure are equivocal about within-ocean population structure (Dufault et al. 1999). However, in the South Pacific, female sperm whales appear quite clearly structured into sympatric cultural clans, each with a distinctive dialect (Rendell \& Whitehead 2003).

While latitudinal movements of mature males are believed to be seasonal (Best 1979), there is rather little evidence for this. Seasonal components of female movement are even less clear (Whitehead 2003). Over most time scales, females seem to operate in a nomadic fashion, moving opportunistically as feeding conditions change. While horizontal speeds through the water are typically about $4 \mathrm{~km} \mathrm{~h}^{-1}$, over scales of a few hours to a few days, movement patterns vary considerably. When feeding is good, the whales turn frequently and when it is poor they use quite straight tracks (Whitehead 2003). Additionally, in the eastern Pacific, the cultural clans have characteristic movement patterns over periods of hours (Whitehead \& Rendell 2004). Over scales of greater than a few days, knowledge of sperm whale movement is much poorer.

Part of the reason for the uncertainty about largescale movement is that the species is not easy to study. It has taken many years to develop effective long-term satellite-monitored tags, and only a few have been successfully deployed (Mate et al. 2007). Some information was gathered during the commercial whaling era by the use of metal tags bearing serial numbers, termed Discovery tags, which were shot into living whales and recovered during the processing of car- casses (Kasuya \& Miyashita 1988). Most usefully, quite large data sets exist of photoidentifications of individuals from a number of locations and over many years in both the North Atlantic and eastern tropical Pacific. However, both the Discovery tags and photoidentifications were distributed very irregularly in both space and time, so are not suitable for most methods of analyzing movements (as described by Turchin 1998). To address these situations, Whitehead (2001) developed likelihood techniques for analyzing animal movements using individual identifications, illustrating them using parts of the sperm whale photoidentification data set for the eastern tropical Pacific.

In the present study, we use 11255 photoidentifications of sperm whales from the tropical Pacific to examine extreme and modal movements over scales of $3 \mathrm{~d}$ to $15 \mathrm{yr}$, and we use tracks of followed groups to describe movements over scales of 1 to $48 \mathrm{~h}$. The movements are described principally using root-meansquare displacements (the square root of mean-square displacement) over a range of temporal scales. Displacement is the straight-line distance between 2 locations of the same individual. Mean-square displacement is a natural component of movement analyses using the random walk paradigm and associated methods (Turchin 1998). Compared with mean displacement, it weights larger movements more heavily, which is perhaps appropriate, as these are disproportionately influential in areas such as population genetics and management. However, squared displacement has no intuitive meaning, so we also present rootmean-square displacement, which estimates actual movement distance. We examine the fit of the data to the correlated random walk model in which organisms make moves with random length and turning angles centered around $0^{\circ}$. We have analyzed some of these data before (Whitehead 1996, 2003, Jaquet et al. 2003, Whitehead \& Rendell 2004), but this analysis goes further, particularly by combining photoidentifications from the Gulf of California with those from other areas, by examining differences between the movements of clans over a range of temporal scales and by comparing movement patterns with those expected from a correlated random walk.

\section{MATERIALS AND METHODS}

Field research and photoidentification. Sperm whales were studied during several field projects between 1985 and 2004 in the South Pacific and Eastern Tropical Pacific (Table 1, Fig. 1). The research vessels generally spent 2 to $4 \mathrm{wk}$ at sea tracking groups of female and immature whales, visually and acoustically (with a directional hydrophone), day and night (see 
Whitehead \& Gordon 1986). Individual groups were usually tracked for 1 to $3 \mathrm{~d}$. A few photoidentifications were also collected opportunistically during passages or surveys conducted by the National Marine Fisheries Service, Southwest Fisheries Science Center (see Jackson et al. 2004). Most of the studies used $35 \mathrm{~mm}$ cameras with fixed $300 \mathrm{~mm}$ lenses and Ilford HP5 black and white film to photograph the sperm whales' flukes, although more recent research (since about 2001) has used digital cameras.

Table 1. Physeter macrocephalus. Number of photoidentifications (quality rating, $Q \geq 3$ ) of female/immature sperm whales (mature males in parentheses) by ocean area (see Fig. 1) and year

\begin{tabular}{|cccccc|}
\hline Year & Galápagos & Ecuador & Chile & $\begin{array}{c}\text { Western } \\
\text { Pacific }\end{array}$ & $\begin{array}{c}\text { Gulf of } \\
\end{array}$ \\
& & & & & \\
\hline 1985 & $791(42)$ & $13(0)$ & $0(0)$ & $0(0)$ & $0(0)$ \\
1987 & $1414(36)$ & $0(0)$ & $0(0)$ & $0(0)$ & $0(0)$ \\
1988 & $296(0)$ & $0(0)$ & $0(0)$ & $0(0)$ & $0(0)$ \\
1989 & $974(30)$ & $0(0)$ & $0(0)$ & $0(0)$ & $0(0)$ \\
1991 & $197(3)$ & $678(13)$ & $0(0)$ & $0(0)$ & $0(0)$ \\
1992 & $0(0)$ & $5(0)$ & $0(0)$ & $222(10)$ & $1(0)$ \\
1993 & $4(0)$ & $240(2)$ & $233(0)$ & $5(0)$ & $2(0)$ \\
1994 & $63(0)$ & $0(0)$ & $0(0)$ & $0(0)$ & $0(0)$ \\
1995 & $526(16)$ & $37(0)$ & $0(0)$ & $0(0)$ & $4(0)$ \\
1996 & $110(7)$ & $0(0)$ & $0(0)$ & $0(0)$ & $0(0)$ \\
1997 & $0(0)$ & $0(0)$ & $0(0)$ & $0(0)$ & $5(0)$ \\
1998 & $48(9)$ & $0(0)$ & $0(0)$ & $0(0)$ & $106(11)$ \\
1999 & $418(3)$ & $6(0)$ & $0(0)$ & $1(0)$ & $305(7)$ \\
2000 & $0(0)$ & $15(0)$ & $1894(105)$ & $0(0)$ & $0(0)$ \\
2002 & $0(69)$ & $0(0)$ & $0(0)$ & $0(0)$ & $700(19)$ \\
2003 & $3(0)$ & $0(0)$ & $0(0)$ & $2(0)$ & $277(12)$ \\
2004 & $0(0)$ & $0(0)$ & $0(0)$ & $0(0)$ & $139(0)$ \\
Total & $4844(215)$ & $994(15)$ & $2127(105)$ & $230(10)$ & $1539(49)$ \\
& & & & & \\
\hline
\end{tabular}

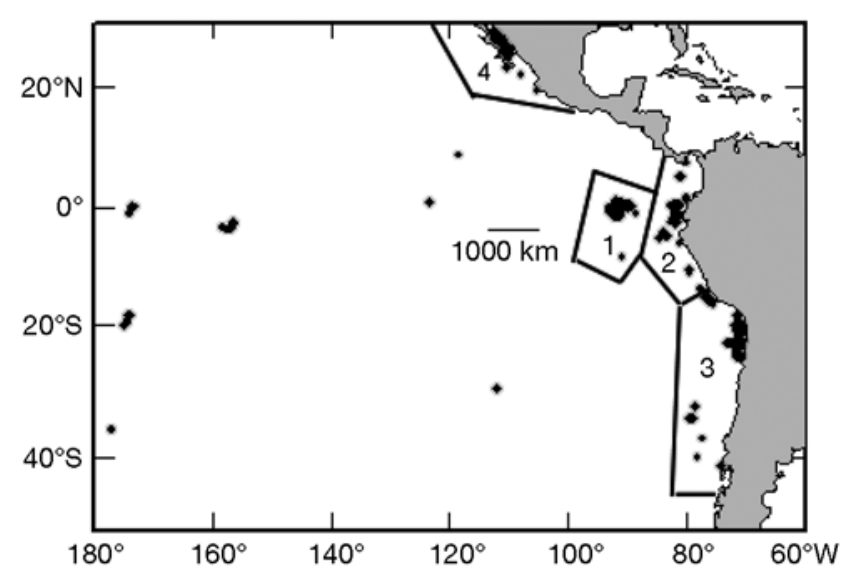

Fig. 1. Physeter macrocephalus. Locations of photoidentifications in general ocean areas of study: Galápagos (1), Panama/ Ecuador/northern Peru (2), Chile/southern Peru (3), Gulf of California (4), and Western Pacific (unbounded areas to the west)
With each photograph was recorded the time, location (using SATNAV until 1991, and GPS thereafter; although locations were not recorded for some photographs from the Galápagos Islands), and whether the whale was a calf (distinctively small animal, less than about 2 yr of age) or mature male (distinctively large animal). Photographs of calves were not used in the movement analysis, and those of mature males were analyzed separately. Whales which were neither calves nor mature males are henceforth referred to as females/immatures.

Individual sperm whales were identified by unique markings on the trailing edge of their tail flukes (as in Arnbom 1987, Dufault \& Whitehead 1995). The quality of each photograph was assessed using the criteria of Arnbom (1987). A quality rating was assigned ranging from $Q=1$ (very poor quality) to $Q=5$ (very high quality). Quality was assessed based on 5 attributes of the photograph: focus, exposure, orientation of the fluke in the frame, percent cover (how much of the frame is covered by the fluke) and tilt of the fluke in relation to the surface of the water. The photographs were rated based on the lowest rating from an individual attribute. Only high quality $(Q \geq 3)$ photographs were used for further analyses. Photoidentifications were matched with the assistance of a computer matching program (updated from that described by Whitehead 1990).

The data recording and photoidentification processes resulted in an Excel database. For each usable photograph of a sperm whale fluke, the database contained the date, time, location (latitude and longitude; occasionally not available), identification number, $Q$ value, and general ocean area (Galápagos Islands, Panama/Ecuador/northern Peru, Chile/southern Peru, Western Pacific or Gulf of California; see Fig. 1 for ocean area). The numbers of photoidentifications with $Q \geq 3$ and recorded positions in each general ocean area in each year are given in Table 1.

Movement analyses over time scales $>\mathbf{3} \mathrm{d}$. We used the photoidentification data from the eastern Pacific to estimate movement rates for female and immature sperm whales (there being insufficient data to do this meaningfully for the western Pacific or for mature males). The output was the estimated root-meansquare displacement over a range of time lags. The root-mean-square displacement is an estimate of the straight-line distance between the 2 locations of a randomly chosen female/immature sperm whale which are separated by a given time lag (e.g. 10 d). These root-mean-square displacements were estimated using the likelihood method of Whitehead (2001). This method uses the photoidentifications themselves as a measure of effort and thus accounts for an irregular and nonrandom spatio-temporal effort distribution. Only lags of $3 \mathrm{~d}$ or more were considered, as groups 
were followed over periods of 1 to $3 \mathrm{~d}$, and the likelihood method is invalid when groups are tracked (Whitehead 2001). To make the calculations feasible on the large data set, time lags and spatial displacements were binned into sets of equal logarithmic size (a factor of 2 for time lags and 1.4 for displacements, as in Whitehead 2001). Sets of lags were lumped to give reasonable sample sizes within the following ranges: 3 to $4 \mathrm{~d}, 5$ to $10 \mathrm{~d}, 11$ to $30 \mathrm{~d}, 31$ to $1000 \mathrm{~d}, 1001$ to $2000 \mathrm{~d}$ and $>2000$ d. Error bars for estimated root-meansquare displacements were calculated using the temporal jackknife method, in which jackknife replicates are calculated by omitting data collected during each $31 \mathrm{~d}$ period in turn.

Off the Galápagos, some of the individual females/ immatures have been allocated to social units (from 'Appendix' in Christal 1998) and, in turn, the clan of most of these units is known from acoustic recordings (Rendell \& Whitehead 2003). These gave photoidentification records of 130 members of the 'Regular' clan and 49 members of the 'Plus-one' clan, the 2 principal clans that use these waters. Photoidentifications of these whales were used even if they had moved to other ocean areas. For this analysis by clan, in addition to the likelihood method that corrects for irregular and nonrandom effort, we present results from the standard calculations of root-mean-square displacement with time lag (which simply considers each pair of photoidentifications of an individual as a data point). Although the results of these standard calculations may be biased because of irregular effort, they can be used to contrast movement patterns, as the effort was the same for the 2 clans. With the smaller sample sizes of the clan analysis, it was possible to use the standard jackknife technique, in which individuals are removed from the analysis in turn to estimate errors. In the analysis by clan, the widths of time lag bins were adjusted to give reasonable sample sizes.

These analyses were carried out using the movement module of the Matlab program SOCPROG (available at http://myweb.dal.ca/hwhitehe/social.htm).

Movement analyses over time scales of $<\mathbf{3}$ d. To analyze movements over scales shorter than $3 \mathrm{~d}$, we used the tracks of the research vessel when following groups of female and immature sperm whales. The tracks were broken into $3 \mathrm{~h}$ segments for SATNAV data (during which, fixes were obtained about every $1.5 \mathrm{~h})$, which included almost all data from the Galápagos and Ecuador. GPS data, with essentially continuous fixes, were broken into $1 \mathrm{~h}$ segments. These data were then lumped into 4, 8, 16, 24 and 48 h segments. Over each time scale, we calculated the root-meansquare displacement over all segments, with standard errors estimated from the variance of separate calculations for each 2 to $3 \mathrm{wk}$ trip at sea. Total tracking time was 202 d (123 d off Galápagos and Ecuador; 68 d off Chile; and $11 \mathrm{~d}$ in the western Pacific).

To investigate differences between the movements of the 2 principal clans off the Galápagos, we used tracking data collected in 1987 and 1989, the 2 years in which numbers of groups of both clans were tracked. Allocation of tracks to clans is as described by Whitehead \& Rendell (2004).

Comparisons with correlated random walk. To examine the fit of the results to the correlated random walk model, we calculated expected squared displacements using 3 move durations: 1, 3 and $48 \mathrm{~h}$. There was no evidence for directional bias in the data (left turns were approximately as frequent as right turns; a sign test did not reject the null hypothesis of equal turn frequency, $p>0.05$ for all move durations). Then, expected squared displacement was calculated using the formula (Eq. 2 of Kareiva \& Shigesada 1983):

$R_{n}{ }^{2}=n \times m_{2}+2 \times m_{1}{ }^{2} \times \psi \times\left[n-\left(1-\psi^{n}\right) /(1-\psi)\right] /(1-\psi)$

where $n$ is the number of moves, $m_{1}$ is the mean move length, $m_{2}$ the mean-square move length, and $\psi$ the mean cosine of the turning angle between adjacent moves. Additionally, we examined 2 assumptions of the correlated random walk: that both move lengths and turning angles were independent.

\section{RESULTS}

\section{Summary of data set}

There were 11255 photoidentifications with $Q \geq 3$ and a recorded location in the data set (Table 1). Additionally there were 1127 photoidentifications with $Q \geq$ 3 but lacking a recorded position from the Galápagos (140 in 1988, 657 in 1989, 13 in 1993, 32 in 1994, 283 in 1997 and 2 in 1998). Positions of photoidentifications with a recorded location are shown in Fig. 1 and the number of whales identified in each general area and year are tabulated in Table 2. In total, 3735 females/ immatures and 154 mature males were photoidentified during the studies by at least one photograph with $Q \geq$ 3 and a recorded location, with substantial numbers of females/immatures identified from the Galápagos or in the Gulf of California during more than 1 yr. Effort was distributed very unevenly both spatially and temporally.

There were 322 (364) females/immatures and 5 (9) mature males identified in more than $1 \mathrm{yr}$, and 51 (60) females/immatures, and 0 (0) mature males identified in more than one general ocean area. Numbers in parentheses in the preceding sentence include photographs without a recorded location. 
Table 2. Physeter macrocephalus. Number of individual female/immature sperm whales (mature males in parentheses) photoidentified $(Q \geq 3)$ by ocean area (see Fig. 1) and year, and the number photographed in each area in more than $1 \mathrm{yr}$

\begin{tabular}{|ccrrrr|}
\hline Year & Galápagos Ecuador & Chile & $\begin{array}{r}\text { Western } \\
\text { Pacific }\end{array}$ & $\begin{array}{c}\text { Gulf of } \\
\text { California }\end{array}$ \\
\hline 1985 & $344(8)$ & $6(0)$ & $0(0)$ & $0(0)$ & $0(0)$ \\
1987 & $440(8)$ & $0(0)$ & $0(0)$ & $0(0)$ & $0(0)$ \\
1988 & $95(0)$ & $0(0)$ & $0(0)$ & $0(0)$ & $0(0)$ \\
1989 & $337(4)$ & $0(0)$ & $0(0)$ & $0(0)$ & $0(0)$ \\
1991 & $94(2)$ & $278(4)$ & $0(0)$ & $0(0)$ & $0(0)$ \\
1992 & $0(0)$ & $5(0)$ & $0(0)$ & $109(5)$ & $1(0)$ \\
1993 & $0(0)$ & $116(1)$ & $114(0)$ & $5(0)$ & $2(0)$ \\
1994 & $23(0)$ & $0(0)$ & $0(0)$ & $0(0)$ & $0(0)$ \\
1995 & $91(8)$ & $21(0)$ & $0(0)$ & $0(0)$ & $4(0)$ \\
1996 & $29(4)$ & $0(0)$ & $0(0)$ & $0(0)$ & $0(0)$ \\
1997 & $0(0)$ & $0(0)$ & $0(0)$ & $0(0)$ & $5(0)$ \\
1998 & $27(6)$ & $0(0)$ & $0(0)$ & $0(0)$ & $64(4)$ \\
1999 & $9(3)$ & $3(0)$ & $0(0)$ & $1(0)$ & $102(3)$ \\
2000 & $0(0)$ & $15(0)$ & $863(32)$ & $0(0)$ & $0(0)$ \\
2002 & $0(37)$ & $0(0)$ & $0(0)$ & $0(0)$ & $280(5)$ \\
2003 & $1(0)$ & $0(0)$ & $0(0)$ & $1(0)$ & $139(4)$ \\
2004 & $0(0)$ & $0(0)$ & $0(0)$ & $0(0)$ & $68(0)$ \\
Total & $1260(76)$ & $443(5)$ & $974(32)$ & $116(5)$ & $563(15)$ \\
$>1 \mathrm{yr}$ & $187(4)$ & $1(0)$ & $3(0)$ & $0(0)$ & $86(1)$ \\
\end{tabular}

\section{Long-distance movements}

Pairs of photoidentifications more than $500 \mathrm{~km}$ apart are linked in Fig. 2a to illustrate long-distance movements. These are summarized in Fig. 2b, which shows movements between ocean areas (including data from identifications without a recorded location) and subareas (the coastal eastern tropical Pacific area is divided into the waters off Panama, Ecuador and northern Peru). As these movements are almost all over 1 yr or more, they contain no information about seasonality. There were no recorded movements of mature males over more than $500 \mathrm{~km}$ in the data set. There were also no movements of more than $500 \mathrm{~km}$ within the western Pacific or from the western Pacific to other areas. The lack of long-distance movements within the western Pacific is expected, as nearly all data from this area were collected over a few months in late 1992 (Table 1). Given the substantial number of long-distance movements recorded in the eastern Pacific (Fig. 2), a lack of any matches in the west indicates that east-west movements of more than $5000 \mathrm{~km}$ are uncommon.

Within the eastern Pacific, movements of about $1000 \mathrm{~km}$ by females/immatures, for instance between the Galápagos and mainland Ecuador or Panama, appear frequent (Fig. 2). In contrast, while movements of about $4000 \mathrm{~km}$ (from Galápagos to the Gulf of California or from Galápagos to Chile) were detected, they seem relatively rare.
Many long-distance movements, perhaps all, were made by several females/immatures together, presumably members of the same social unit (Christal et al. 1998). Two movements were defined as 'together,' when both the first and the second identifications of the respective movements were within $3 \mathrm{~d}$ of one
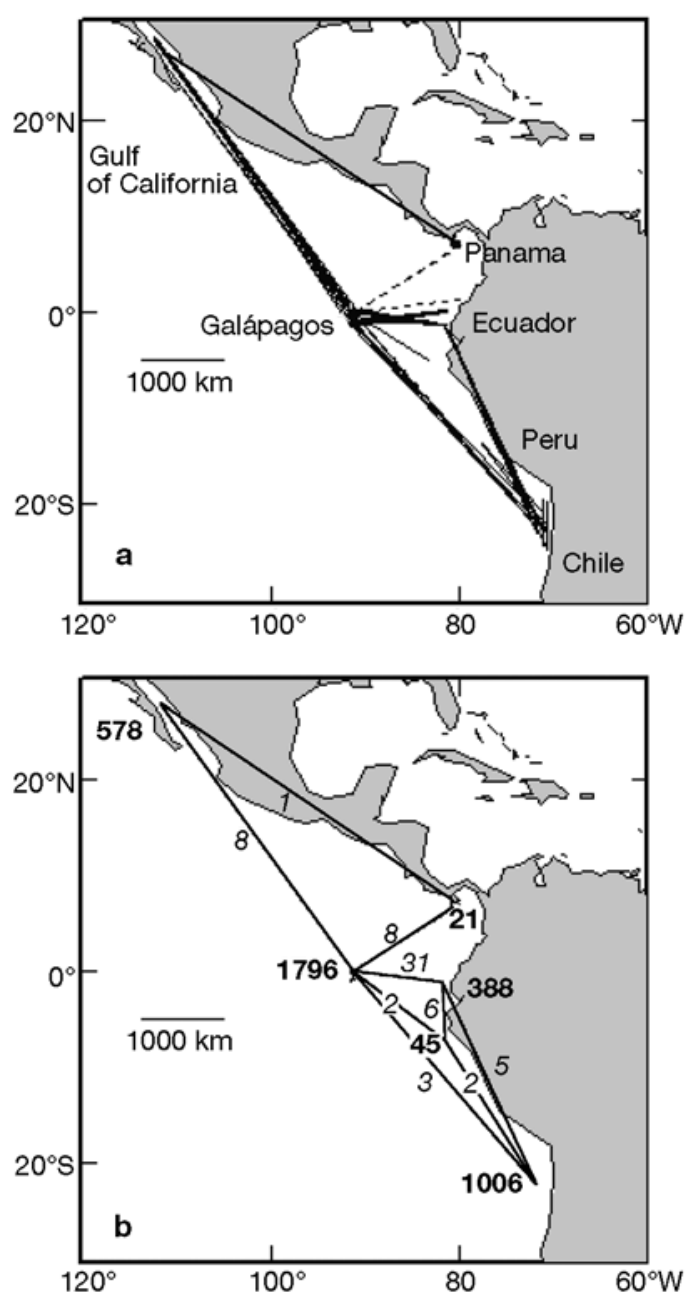

Fig. 2. Physeter macrocephalus. Movements of photoidentified female/immature sperm whales in the eastern tropical Pacific and neighboring waters. (a) Links between photoidentifications of the same whale more than $500 \mathrm{~km}$ apart. If 2 movements of the same whale are such that the first sightings of each movement are less than 1 mo apart and the second sightings of each movement are less than 1 mo apart, only the first movement is shown. Dashed lines represent links for which there is no recorded location at one end of a match (just off Galápagos Islands for which the location was assigned to $0^{\circ} \mathrm{N} 91^{\circ} \mathrm{W}$, approximately the centre of the Galápagos study area). (b) Number of individuals identified in pairs of areas and subareas (the coastal eastern tropical Pacific area is divided into the waters off Panama, Ecuador and northern Peru). Bold numerals indicate number of individuals identified in each area or subarea; italic numerals indicate number of individuals moving between them 
another. There were 95 individual movements of more than $500 \mathrm{~km}$ (excluding duplicate movements in which there was another movement of the same individual recorded such that the first identifications were within $30 \mathrm{~d}$ of one another, and the second identifications were within $30 \mathrm{~d}$ of one another). In these, a mean of 2.4 whales (range 1 to 8) were identified moving together at a time. This underestimates the number of whales that travel together, as we were often unable to identify whales at one or both ends of a movement.

\section{Displacements with time lag}

The patterns of movement indicated by the longdistance matches in Fig. 2 are a function of the spatial and temporal distribution of effort, which was very uneven (Table 1). Thus, we estimated the rates of movement by female and immature sperm whales over time scales greater than $3 \mathrm{~d}$ in the Pacific using the likelihood method described by Whitehead (2001) and summarized in 'Materials and methods.' This technique accounts for irregularity of effort. Movements over scales less than $3 \mathrm{~d}$ were estimated from the tracks of followed groups. These data do not need to be standardized for effort and are considerably more precise.

The female/immature identifications in the eastern tropical Pacific indicate a rising displacement with time lag (Fig. 3). On average, a female/immature dis- placement is about $4 \mathrm{~km}$ after $1 \mathrm{~h}$ of movement, $50 \mathrm{~km}$ after $1 \mathrm{~d}$ of movement, $200 \mathrm{~km}$ after $3 \mathrm{~d}$ of movement and about $1000 \mathrm{~km}$ after $1 \mathrm{yr}$ of movement. Reassuringly, the estimated displacement at $2 \mathrm{~d}$ of movement from the tracking data is consistent with that of $3 \mathrm{~d}$ from the photoidentification data.

There is a substantial contrast between the movements of members of the 2 principal clans which use Galápagos waters (Fig. 4). It already had been shown that groups of the 'Plus-one' clan had significantly greater displacements over scales of $12 \mathrm{~h}$ than those of the 'Regular' clan (Whitehead \& Rendell 2004). The substantially greater movements of the 'Plus-one' groups are now apparent over all scales, from $6 \mathrm{~h}$ to $5 \mathrm{yr}$ (Fig. 4). Over $3 \mathrm{~h}$ there is little difference between the clans, indicating that their speeds of travel through the water are similar, but the tracks of the 'Plus-one' groups are much straighter over scales of days (see Whitehead 2003 for some examples). These differences are propagated into contrasts in displacement over longer time durations (Fig. 4). Both likelihood and direct estimates of displacement over scales of days to years are shown for the 2 clans in Fig. 4. While the direct estimates are much more precise, they may be biased. However, the biases will be similar for both clans and the ca. $50 \%$ greater displacements of members of the 'Plus-one' clan are very apparent.

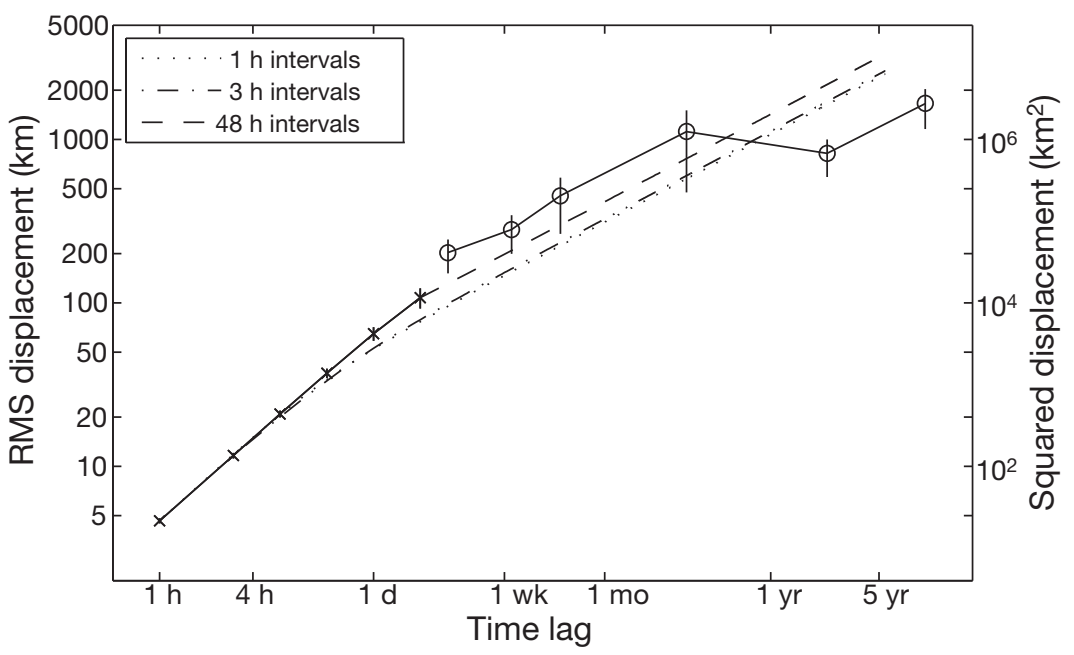

Fig. 3. Physeter macrocephalus. Estimated root-mean-square (RMS) displacement (and squared displacement, right axis) plotted against time lag for female/immature sperm whales in the eastern tropical Pacific. O: over time scales greater than $3 \mathrm{~d}$, estimates were obtained using maximum likelihood (Whitehead 2001) and photoidentification data (SE estimated using the temporal jackknife method). $\times$ : over time scales of less than $3 \mathrm{~d}$, estimates were obtained from continuous tracks of groups of females/immatures (SE estimated using variation in estimates from different 2 to 3 wk periods at sea). Also shown, as dashed and dotted lines, are expected displacements from correlated random walk models using move durations of 1,3 and $48 \mathrm{~h}$

\section{Correlated random walk}

Expected displacements under the correlated random walk, calculated using Eq. (1) for move durations of 1, 3 and $48 \mathrm{~h}$, are overlaid on the estimated root-mean-square displacements of the whales in Fig. 3. Under the correlated random walk, over durations of more than a few moves, squared displacement is expected to rise approximately linearly with time lag (see Eq. 1). However, over scales of about $12 \mathrm{~h}$ to $2 \mathrm{~d}$ the female/immature sperm whales moved further than expected under the correlated random walk (Fig. 3). This seems to be largely because of autocorrelation in move lengths (e.g. $r=0.40, p=0.000$, for moves of length $3 \mathrm{~h} ; r=0.85, \mathrm{p}=0.000$, for moves of length $12 \mathrm{~h}$ ); there were times, for instance when feeding conditions were poor, when groups consistently made large displacements, and others when they were consistently small (Whitehead 1996). This 


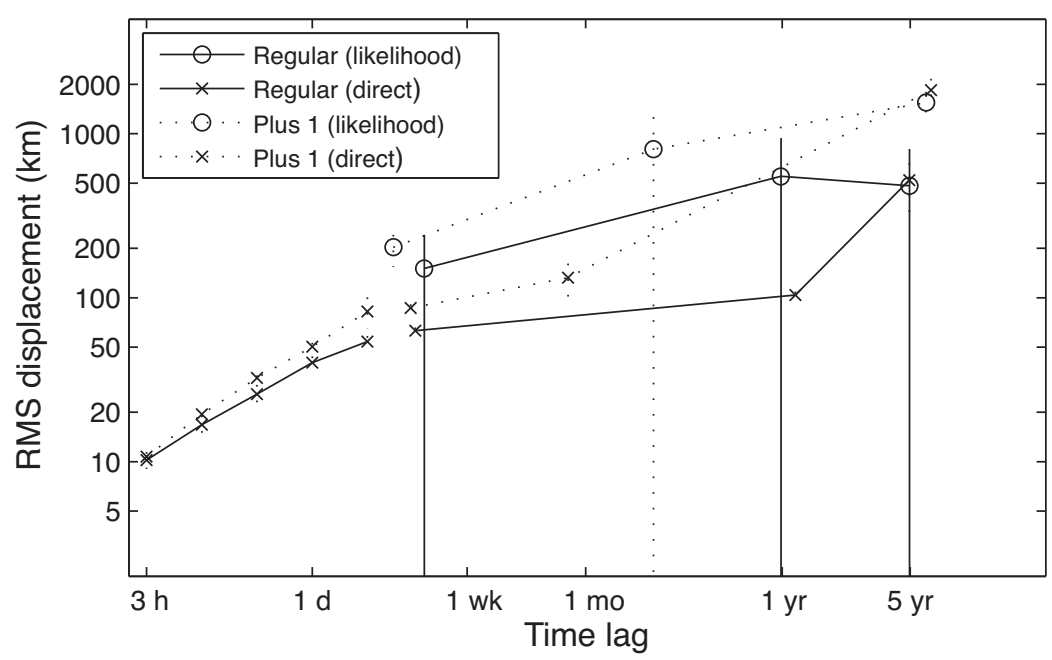

Fig. 4. Physeter macrocephalus. Estimated root-mean-square (RMS) displacements plotted against time lag for females/immatures of 2 different clans. Over time scales greater than $3 \mathrm{~d}$, estimates were obtained from photoidentification data using both the direct method $(\times)$, which assumes uniform or random spatial distribution of effort and maximum likelihood (O) (Whitehead 2001). SE estimated using the jackknife method, in which individuals were omitted from the analysis in turn. Over time scales of less than $3 \mathrm{~d}$, estimates were obtained from continuous tracks of groups of females/immatures off the Galápagos Islands in 1987 and 1989 (SE estimateds using variation in estimates from different 2 to 3 wk periods at sea)

effect outweighs a general autocorrelation in turning direction, with right turns following right turns, and left following left, more often than vice versa $(9 \%$ fewer changes in turn direction than expected with $3 \mathrm{~h}$ move durations; $p=0.0011$, runs test; $17 \%$ fewer changes in turn direction than expected with $12 \mathrm{~h}$ move durations; $p=0.0000$, runs test). Thus tracks tended to follow broad arcs.

Over scales of a few days to a few weeks, squared displacement rose approximately linearly with time lag, as expected in a correlated random walk (Fig. 3). However, displacement rose less fast than expected over lags of years, indicating preferred home ranges.

\section{DISCUSSION}

\section{Methodology}

It is general practice to use satellite telemetry to study the movements of cetaceans and other larger marine organisms (e.g. Wilson et al. 1997, Mate et al. 2007). However, there are alternatives, 2 of which are used in this study: repeat identifications of individuals and acoustic tracking. For sperm whale groups, acoustic tracking works well over periods of up to a few days, but there are, we think, no species with as consistent and loud an acoustic signal as a sperm whale group. Attachment of acoustic transmitters is sometimes a workable substitute (e.g. Voegeli et al. 2001), but there is still the logistic expense of the tracking vessel, limiting tracking times to days in most cases. Over longer time scales, repeat identifications of individuals using natural or artificial markings can be a very effective way to study movements, and a useful alternative or adjunct to satellite tracking for many species. Few other methods can track movements over several years or easily integrate data from a number of different types of study. The principal drawback of repeat identification data, the irregular and non-random spatial and temporal distribution of effort, can be dealt with by likelihood methods (Whitehead 2001), as in this study. However, these likelihood techniques reduce statistical power, necessitating large data sets.

Whichever method is used to collect the data, their value can be greatly enhanced by fitting models, such as correlated random walks. For instance, using movement analysis, Bailey \& Thompson (2006) identified important foraging sites of bottlenose dolphins Tursiops truncatus and Austin et al. (2004) separated satellite-tracked grey seals Halichoerus grypus into 3 quite different types of forager.

\section{Sperm whale movement patterns}

Mature male sperm whales are scarce in the eastern tropical Pacific. This is largely because of their high latitudinal non-breeding distribution, late age of return to the breeding areas (ca. 27 yr, Best 1979) and probable higher mortality (International Whaling Commission 1980). However, the lingering effects of intense male-biased whaling in the area may also play a role (Whitehead et al. 1997). A result of this scarcity is that there are rather few photoidentifications of males in our data set (Tables 1 \& 2) and we can say little about their movements. Tracking using satellite tags (Mate et al. 2007), or inferences from isotope analyses (e.g. Mendes et al. 2007), may be the most promising ways to investigate the large-scale movements of male sperm whales.

In contrast, this analysis, together with its predecessors (Whitehead 1996, 2003, Whitehead \& Rendell 2004), has provided a fairly clear model of the move- 
ments of female and immature sperm whales in the region. It seems to consist of the following elements (updated from Whitehead 2003):

(1) A horizontal transit speed of about $4 \mathrm{~km} \mathrm{~h}^{-1}$ (Fig. 3). Net energy gain is expected to be a convex function of search speed (Ware 1975), so from an evolutionary perspective, a reasonable hypothesis is that $4 \mathrm{~km} \mathrm{~h}^{-1}$ maximizes this net energy gain for sperm whales.

(2) Over periods of hours to $1-2 \mathrm{~d}$, a fairly straight track, or broad arc, when feeding conditions are poor and a recurving track when they are good. Off Chile, mean turning angles between hours were about $18^{\circ}$ $\mathrm{h}^{-1}$ when feeding conditions (as indicated by defecation rates) were poor and $30^{\circ} \mathrm{h}^{-1}$ when they were good (Whitehead 2003). Displacements averaged about $50 \mathrm{~km}$ after $24 \mathrm{~h}$ (Fig. 3). Mean displacements are greater than expected under the correlated random walk over these time scales largely because of autocorrelation in small-scale displacements (Fig. 3), which in turn largely stem from the differences in movement with feeding success (Whitehead 1996). The pattern of staying when feeding is good and moving when it is poor is expected theoretically (Charnov 1976) and found in many other organisms (Mayo \& Marx 1990, Gutenkunst et al. 2007).

(3) Movements consistent with expectations from the correlated random walk over periods of a few days to a few months, with whales covering several hundred kilometers (Fig. 3). The whales probably do not move randomly, but the interplay of a number of factorsincluding reactions to changes in current feeding success, as well as perceptions and memory about optimal foraging areas - produce movement patterns that are not distinguishable from random in our data. We do not know how sperm whales navigate.

(4) Effects of geographical and oceanographic constraints such as land, shallow water and the shapes and sizes of productive oceanographic regions. For instance, in the Gulf of California movements are constrained by land, and off Chile productivity is focused on the northward-moving Humboldt Current, producing larger north-south movements than east-west movements (Whitehead 2003).

(5) Cultural determination of movement over most scales. Previously, cultural differences in group movement have been shown for sperm whale clans only over periods of $12 \mathrm{~h}$ (Whitehead \& Rendell 2004), but they also exist over scales from $6 \mathrm{~h}$ to several years (Fig. 4).

(6) Overall, displacements of ca. $1000 \mathrm{~km}$ over periods of years, with displacement rising less fast than predicted by the correlated random walk (Fig. 3). This suggests home ranges spanning about $2200 \mathrm{~km}$ (as the mean distance between 2 randomly selected points in a circle is 0.45 of its diameter, Whitehead 2003). This is rather larger than the $1450 \mathrm{~km}$ estimated by Whitehead (2003) using a subset of our data, which did not include the identifications from the Gulf of California. Home ranges spanning about $2000 \mathrm{~km}$ may be related to the amount of habitat that an individual or a social unit can keep track of.

(7) Occasional long-distance movements by a few animals spanning about $4000 \mathrm{~km}$, but rarely further (Fig. 2).

The conclusions about sperm whale movements derived in this study refer only to the tropical Pacific. They are consistent with some data from other oceans using other methods. For instance, many of the female/ immature sperm whales tagged with metal cylinders in the North Pacific were later recovered by whaling operations 200 to $2000 \mathrm{~km}$ away, with occasional movements of about $4000 \mathrm{~km}$ (Kasuya \& Miyashita 1988). For the 22 females tagged in the Southern Ocean who were captured at least 1 mo later, the mean distance between tagging and capture was $690 \mathrm{~km}$ (Best 1979). In contrast, a preliminary analysis of photoidentifications of female/immature sperm whales in the eastern Caribbean suggests more restricted movements and ranges, with whales being repeatedly reidentified over periods of years within $100 \mathrm{~km}$ (Gero et al. 2007).

\section{Implications}

These results indicate that social units and groups of female/immature sperm whales adapt their movements over a range of temporal and spatial scales to the distribution of resources. It appears that only over time scales of years or more, and spatial scales of more than $1000 \mathrm{~km}$, are movements constrained by factors other than bathymetry and oceanography.

Such behavior promotes efficient use of resources and thus likely contributes to the sperm whales' ecological dominance (see Clarke 1977). Wide-ranging, resource-based movement leads to density-dependent habitat selection, which has implications for management (MacCall 1990). Perhaps most importantly, with density-dependent habitat selection, rates of decline in catch-per-unit-effort will tend to be less pronounced than rates of decline in population size when exploitation is not geographically uniform (Whitehead 2000). In the eastern tropical Pacific, modern sperm whaling was particularly heavy in the waters off Chile and Peru (see Clarke et al. 1980, Ramirez 1989), but catch-perunit-effort statistics did not decline dramatically, presumably because of individuals moving into the whaling area from unexploited regions to the west (Whitehead et al. 1997). 
Wide-ranging, adaptive movement complicates management (e.g. Musick et al. 2000). In the case of the sperm whale, occasional movements of about $4000 \mathrm{~km}$ (Fig. 2) will contribute to genetic homogenization within ocean basins (Lyrholm et al. 1999) and difficulty in defining robust management areas (Donovan 1991). For instance, the division between two of the International Whaling Commission's sperm whale 'stocks' lies along the equator in the eastern tropical Pacific, a boundary which makes no sense given the movements shown in Fig. 2. The results of this study reinforce the argument that cultural divisions of sperm whale populations may be more appropriate than geographical ones (Whitehead et al. 2004).

Acknowledgements. Thanks to our colleagues who helped collect the data, especially D. Gendron and G. Merlen, both of whom contributed photographs and assisted in a variety of ways. T. Lyrholm, as well as P. Olson and T. Gerrodette of the US National Marine Fisheries Service (Southwest Fisheries Science Center, La Jolla, CA), also contributed photographs. T. Arnbom, S. Waters, S. Dufault and J. Christal analyzed the earlier photoidentifications. The research was funded by the Whale and Dolphin Conservation Society, the Natural Sciences and Engineering Research Council of Canada, the National Geographic Society, the International Whaling Commission, Cetacean Society International, the Island Foundations, the Center for Field Research, the Wildlife Conservation Society, Comisión National para el Conocimiento y Uso de la Biodiversidad, Mexico, the Société Académique Vaudoise, Switzerland, and the Sierra Club. The Galápagos National Park Service, the Armada of Ecuador, the Charles Darwin Research Station, the Instituto Nacional de Pesca of Ecuador and the Chilean Antarctic Institute helped with permits and in other ways. The Centro Interdisciplinario en Ciencias Marinas, Instituto Politécnico National, La Paz, Mexico, loaned equipment, as well as their research vessel, for 2 seasons in the Gulf of California. Thanks to 5 reviewers for their useful comments.

\section{LITERATURE CITED}

Arnbom T (1987) Individual identification of sperm whales. Rep Int Whal Comm 37:201-204

Austin D, Bowen WD, McMillan JI (2004) Intraspecific variation in movement patterns: modelling individual behaviour in a large marine predator. Oikos 105:15-30

Bailey H, Thompson P (2006) Quantitative analysis of bottlenose dolphin movement patterns and their relationship with foraging. J Anim Ecol 75:456-465

Best PB (1979) Social organization in sperm whales, Physeter macrocephalus. In: Winn HE, Olla BL (eds) Behavior of marine animals, Vol 3. Plenum, New York, p 227-289

Best PB, Canham PAS, Macleod N (1984) Patterns of reproduction in sperm whales, Physeter macrocephalus. Rep Int Whal Comm (Spec Iss) 6:51-79

Bridle JR, Hayes TH (2007) Limits to evolution at range margins: When and why does adaptation fail? Trends Ecol Evol 22:140-147

Charnov EL (1976) Optimal foraging: the marginal value theorem. Theor Popul Biol 9:129-136

Christal J (1998) An analysis of sperm whale social structure: patterns of association and genetic relatedness. $\mathrm{PhD}$ thesis, Dalhousie University, Halifax

Christal J, Whitehead H, Lettevall E (1998) Sperm whale social units: variation and change. Can J Zool 76: 1431-1440

Clarke MR (1977) Beaks, nets and numbers. Symp Zool Soc Lond 38:89-126

Clarke R, Paliza O, Aguayo L A (1980) Some parameters and an estimate of the exploited stock of sperm whales in the southeast Pacific between 1959 and 1961. Rep Int Whal Comm 30:289-305

Donovan GP (1991) A review of IWC stock boundaries. Rep Int Whal Comm (Spec Iss) 13:39-68

> Dufault S, Whitehead H (1995) An assessment of changes with time in the marking patterns used for photo-identification of individual sperm whales, Physeter macrocephalus. Mar Mamm Sci 11:335-343

Dufault S, Whitehead H, Dillon M (1999) An examination of the current knowledge on the stock structure of sperm whales (Physeter macrocephalus) worldwide. J Cetacean Res Manag 1:1-10

Emlen ST (1991) Evolution of cooperative breeding in birds and mammals. In: Krebs JR, Davies NB (eds) Behavioural ecology. An evolutionary approach, 3rd edn. Blackwell, Oxford, p 301-337

Gero S, Gordon J, Carlson C, Evans P, Whitehead H (2007) Population estimate and inter-island movement of sperm whales, Physeter macrocephalus, in the Eastern Caribbean. J Cetacean Res Manag 9:143-150

Gutenkunst R, Newlands N, Lutcavage M, Edelstein-Keshet L (2007) Inferring resource distributions from Atlantic bluefin tuna movements: an analysis based on net displacement and length of track. J Theor Biol 245:243-257

International Whaling Commission (1980) Report of the Special Meeting on Sperm Whale Assessments, La Jolla, 27 November to 8 December 1978. Rep Int Whal Comm (Spec Iss) 2:107-136

Jackson A, Gerrodette T, Chivers S, Lynn M, Olson P, Rankin S (2004) Marine mammal data collected during a survey in the eastern tropical Pacific Ocean aboard the NOAA ships McArthur II David Starr Jordan, July 29-December 10, 2003. Department of Commerce, NOAA Tech Mem. NOAA-NMFS-SWFSC-366

Jaquet N, Gendron D, Coakes A (2003) Sperm whales in the Gulf of California: Residency, movements, behavior, and the possible influence of variation in food supply. Mar Mamm Sci 19:545-562

Kareiva PM, Shigesada N (1983) Analyzing insect movement as a correlated random walk. Oecologia 56:234-238

Kasuya T, Miyashita T (1988) Distribution of sperm whale stocks in the North Pacific. Sci Rep Whales Res Inst Tokyo 39:31-75

Lyrholm T, Leimar O, Johanneson B, Gyllensten U (1999) Sex-biased dispersal in sperm whales: contrasting mitochondrial and nuclear genetic structure of global populations. Proc R Soc Lond B Biol Sci 266:347-354

MacCall AD (1990) Dynamic geography of marine fish populations. Washington Sea Grant, University of Washington Press, Seattle, WA

Mate B, Mesecar R, Lagerquist B (2007) The evolution of satellite-monitored radio tags for large whales: one laboratory's experience. Deep-Sea Res II 54:224-247

Mayo CA, Marx MK (1990) Surface foraging behavior of the North Atlantic right whale and associated plankton characteristics. Can J Zool 68:2214-2220

> Mendes S, Newton J, Reid RJ, Zuur AF, Pierce GJ (2007) Stable carbon and nitrogen isotope ratio profiling of sperm 
whale teeth reveals ontogenetic movements and trophic ecology. Oecologia 151:605-615

Musick JA, Burgess G, Cailliet G, Camhi M, Fordham S (2000) Management of sharks and their relatives (Elasmobranchii). Fisheries 25:9-13

Ramirez P (1989) Captura de cachalote en Paita: 1976-1981. Bol Lima 63:81-88

Rendell L, Whitehead H (2003) Vocal clans in sperm whales (Physeter macrocephalus). Proc R Soc Lond B Biol Sci 270: 225-231

Soulé ME, Gilpin ME (1991) The theory of wildlife corridor capability. In: Saunders DA, Hobbs RJ (eds) Nature conservation. 2. The role of corridors. Surrey Beatty, Chipping Norton, p 3-8

Sutherland WJ (1996) From individual behaviour to population ecology. Oxford University Press, Oxford

Turchin P (1998) Quantitative analysis of movement. Sinauer Associates, Sunderland, MA

Voegeli FA, Smale MJ, Webber DM, Andrade Y, O'Dor RK (2001) Ultrasonic telemetry, tracking and automated monitoring technology for sharks. Environ Biol Fishes 60: 267-282

Ware DM (1975) Growth, metabolism, and optimum swimming speed of a pelagic fish. J Fish Res Board Can 32:33-41

Whitehead H (1990) Computer assisted individual identification of sperm whale flukes. Rep Int Whal Comm (Spec Iss) 12:71-77

Whitehead H (1996) Variation in the feeding success of sperm

Editorial responsibility: Rory Wilson,

Swansea, UK whales: temporal scale, spatial scale and relationship to migrations. J Anim Ecol 65:429-438

Whitehead H (2000) Density-dependent habitat selection and the modeling of sperm whale (Physeter macrocephalus) exploitation. Can J Fish Aquat Sci 57:223-230

Whitehead H (2001) Analysis of animal movement using opportunistic individual-identifications: application to sperm whales. Ecology 82:1417-1432

Whitehead H (2003) Sperm whales: social evolution in the ocean. University of Chicago Press, Chicago, IL

Whitehead H, Gordon J (1986) Methods of obtaining data for assessing and modelling sperm whale populations which do not depend on catches. Rep Int Whal Comm (Spec Iss) 8:149-166

Whitehead H, Rendell L (2004) Movements, habitat use and feeding success of cultural clans of South Pacific sperm whales. J Anim Ecol 73:190-196

> Whitehead H, Christal J, Dufault S (1997) Past and distant whaling and the rapid decline of sperm whales off the Galápagos Islands. Conserv Biol 11:1387-1396

Whitehead H, Rendell L, Osborne RW, Würsig B (2004) Culture and conservation of non-humans with reference to whales and dolphins: review and new directions. Biol Conserv 120:427-437

Wilson RP, Putz K, Peters G, Culik B, Scolaro JA, Charrassin JB, Ropert-Coudert Y (1997) Long-term attachment of transmitting and recording devices to penguins and other seabirds. Wildl Soc Bull 25:101-106

Submitted: September 18, 2007; Accepted: January 21, 2008 Proofs received from author(s): May 20, 2008 